\title{
Concepções criticas sobre tecnologias digitais de informação e comunicação e processos de ensinar e aprender: contribuições possiveis para as práticas pedagógicas
}

Critical conceptions about digital information and communication technologies and processes of teaching and learning: possible contributions to teaching practices

Sonia Regina Mendes dos Santos ${ }^{1}$

Diego Ferreira ${ }^{2}$

Patricia Maneschy ${ }^{3}$

\section{Resumo}

O objetivo deste artigo é, em primeiro lugar, levantar um debate epistemológico em torno da tecnologia, de seu uso, de críticas a ela e de alternativas emergentes e, em segundo lugar, mas em conexão com o primeiro, em especial com sua última seção, analisar sua aplicação na educação e seus efeitos sobre a aprendizagem. Os vácuos, limites e possibilidades aí existentes serão discutidos à luz de autores nacionais e estrangeiros que trazem contribuições epistemológicas, pedagógicas e filosóficas sobre TDIC e, num segundo momento, à discussão em torno da aprendizagem e do ensino com TDIC sob suas formas digitais e as ferramentas que lhes dão suporte. Preconizamos, por fim, uma Teoria Crítica da Tecnologia, conforme Feenberg, na direção de abordagens também críticas, tanto nas pesquisas quanto no planejamento e utilização das TDIC na educação. A superação dos determinismos tecnológicos, bem como das visões instrumentalista e substancialista relativas às tecnologias digitais se

\footnotetext{
${ }^{1}$ Professora Assistente do Programa de pos-graduçao em Educação/ UNESA

2 Professor substituto na Universidade de Lille, França, no Departamento de Ciências da Educação. Pós-doutor em educação pela USP. Doutor e mestre em educação pela UFF.

${ }^{3}$ Professora adjunta do Programa de Pos-graduação em Ensino de Ciências / IFRJ
}

Interfaces da Educ., Paranaíba, v.11, n.32, p. 735 - 763, 2020 
colocam como elementos imperiosos na propulsão de práticas didáticopedagógicas inovadoras e dos ideários democráticos e humanistas.

Palavras-chave: Tecnologias digitais de informação e comunicação. Cultura digital. Ensino-aprendizagem. Práticas pedagógicas. Didática.

\section{Abstract}

The objective of this article is, in the first place, to raise an epistemological debate around technology, its use, criticism of it and emerging alternatives and, secondly, but in connection with the first, especially its last section, to analyze its application in education and its effects on learning. The present voids, limits and possibilities will be discussed in the light of national and foreign authors who bring epistemological, pedagogical and philosophical contributions to the issue and, in a second moment, to the discussion around learning and teaching with ICT in its digital forms and the tools that support them. Finally, we advocate a Critical Theory of Technology, according to Feenberg, in the direction of approaches that are also critical, both in research and in the planning and use of ICT in education. Overcoming technological determinisms, as well as instrumentalist and substantialist views on digital technologies, are imperative elements in propelling innovative teaching practices and of democratic and humanist ideals.

Keywords: Information and communication technology. Digital culture. Teaching-learning. Teaching practices. Didactics. 


\section{Introdução}

Um amplo debate em torno dos efeitos do uso de tecnologias digitais de informação e comunicação (TDIC) na educação vem ocorrendo há pelo menos duas décadas, considerando-se, sobretudo, a vivência dos alunos em um ambiente eivado de recursos tecnológicos. Selwin (2017, p. 1) diz que “[...] o uso da tecnologia em contextos educacionais parece ter se tornado tão corriqueiro, que, para muitos, entrou no universo do senso comum", tido como inevitável no processo educacional, de modo que não tem sido analisado criticamente. Assim, segundo o autor, as tecnologias são vistas como base para o desenvolvimento de processos e atividades em escalas mais amplas, mais rápidas e mais poderosas do que antes, de modo que os indivíduos têm mais controle e flexibilidade na sua utilização, associando-as a "[...] formas dramaticamente melhoradas e aprimoradas de fazer as coisas" (SELWIN, 2017, p. 27).

As tecnologias digitais possuem características que marcam os modos de transmissão da informação, perpassadas por uma lógica de compartilhamento em que é possivel a construção de rede de "muitos para muitos", o que influencia de forma decisiva seu uso em contextos educacionais. Selwin (2017) acrescenta que as

\footnotetext{
“[...] tecnologias educacionais não são, simplesmente, ferramentas neutras usadas de formas benignas em contextos educacionais. Como quaisquer outras tecnologias, a tecnologia educacional está intrinsecamente associada a aspectos sociais, culturais, econômicos e políticos da sociedade" (SELWIN, 2017, p. 38).
}

Em virtude do exposto, as oscilações e abordagens sobre as tecnologias educacionais são diversas: de defesa da sua supremacia à relativização de sua eficácia; de análises críticas, algumas considerando sua utilização, outras não. Essa multiplicidade de compreensões e em torno da questão se manifesta também por meio de órgãos internacionais voltados à educação. Um relatório da Unesco (PELGRUM; LAW, 2003, p. 7), por exemplo, reconhece que, por um lado, incluir computadores e outros materiais tecnológicos nas escolas custa caro e que os problemas para integrá-los são complexos e diferentes de um país para outro, em razão da Interfaces da Educ., Paranaíba, v.11, n.32, p. 735 - 763, 2020 
diversidade socioeconômica existente; por outro lado, aponta, baseando-se nos estudos qualitativos que compõem o relatório, o que considera vantagens evidentes da associação TDIC-Educação: motivação, prazer de aprender; autoestima; desenvolvimento de competências em TDIC; ampla aptidão ao trabalho colaborativo; melhora da aprendizagem em todas as disciplinas; competência para construir e analisar dados; melhora das competências metacognitivas. A aprendizagem ativa é aí valorizada. Essa perspectiva apoia com mais frequência o trabalho do professor (PELGRUM; LAW, 2003, p. 41) que usa a tecnologia e os recursos digitais. Mas, o relatório apresenta também alguns efeitos negativos detectados na relação TDIC, trabalho pedagógico centrado no aluno, e avaliação tradicional. Um estudo nele referido (PELGRUM; LAW, 2003, p. 47) mostra que, habituados com a obtenção facilitada de informações, graças às tecnologias digitais, os alunos tendem a estudar menos, comprometendo, por consequência, sua "aprendizagem eficaz". Enfim, o relatório mostra que é de difícil definição as vantagens e inconvenientes das TDIC. Os estudos não se baseiam em metodologias equivalentes e apresentam resultados que divergem por variadas razões.

Tais apontamentos elucidam a possibilidade e a necessidade de mais pesquisas sobre o tema. Além daquelas ligadas aos efeitos sobre a aprendizagem e o ensino, há um investimento importante em escala mundial em pesquisas de novas didáticas com o uso de TDIC, com atenção crescente às ferramentas mais recentes, caso dos tablets (GIROUX et al. 2013; HAMON; VILLEMONTEIX, 2015) e dos celulares em suas versões "inteligentes". Sobre eles, seu uso pedagógico em colégios foi debatido em estudo brasileiro (SALATINO; BUENO, 2015). Outra pesquisa, dessa vez espanhola (MARCELO; RIJO, 2019), debate igualmente a apropriação e utilização de recursos tecnológicos no ensino superior. Em ambos os casos, no brasileiro e no espanhol, constatamos a necessidade de qualificação do uso pedagógico daqueles recursos. No primeiro, pelos professores, no segundo, pelos alunos. Por meio dessas pesquisas, aprendemos que há 
dispersão e ampla margem para que a utilização pedagógica dos recursos seja aprimorada.

Mas o que há de comum entre os quatro últimos estudos mencionados? Eles trazem, ainda que abordando aspectos diferentes metodológicos, pedagógicos, didáticos - um esforço de análise crítica sobre o uso das TDIC na educação básica e na superior. Apesar disso, essa não tem sido a linha mais comumente adotada nos estudos da área: Ferreira, Rosado e Carvalho (2017) mostram que as TDIC são predominantemente apresentadas como benéficas para a educação; inerentes, como ferramentas, no campo científico e profissional. Portanto, são mais frequentes as concepções acríticas, sinalizam os autores.

Entretanto, estudar a eficácia do uso de TDIC na aprendizagem ou na ação pedagógica, como preconiza Zaslavsky (2017), prescinde a crítica? Quer dizer, não podemos criticar eventual inadequação didática de certa ferramenta digital e apontar novas pistas a serem exploradas? Além disso, por mais dura que seja, às vezes, a crítica se encerra em si mesma e não poderia abarcar as contradições, limites, mas também possibilidades didático-pedagógicas das TDIC na educação? Essas questões exprimem contradições que este artigo pretende explorar sob duas perspectivas: em primeiro momento, trazendo uma leitura crítica sobre a apropriação e uso das TDIC na nossa sociedade por meio dos trabalhos de Andrew Feenberg (2003, 2015) e Neil Selwyn (2008, 2017); em segundo, em conexão com o primeiro, apresentando-se alguns trabalhos (BRUNER, 1983; CHOUINARD, 1998; KNOERR, 2005; SALATINO; BUENO, 2015; DALLE, 2015; FLUCKIGER, 2017; GUILBAULT; VIAU-GUAY, 2017; MANSOURI, 2019) que indicam as possibilidades para aprendizagem e ensino por meio de TDIC. Analisá-los será interessante para mostrar as pistas ainda a explorar, com cada vez mais frequência, tais como: as questões didáticas que se colocam e, também, aquelas que não são postas; a razão pela qual se deve superar os limites de trabalhos sobre TDIC focados tão somente em suas eficácias; e, por fim, a necessidade de mais empenho nos estudos sobre questões didático-pedagógicas, isso sob o princípio de mais voz regulativa (LOPES, Interfaces da Educ., Paranaíba, v.11, n.32, p. 735 - 763, 2020 
2015) aos professores e, por consequência, aos alunos, com mediação do professor e a argumentação do aluno como elementos pedagógicos essenciais.

\section{TDIC: o debate na perspectiva critica}

Algumas constatações do artigo de Rosado, Ferreira e Carvalho (2017) foram essenciais para que começássemos os estudos sobre as questão levantadas e por consequência a redação deste ensaio. Diversas abordagens teóricas de diferentes disciplinas são levadas em conta nas pesquisas da área; há fragilidade teórico-metodológica nos estudos sobre TDIC; elas são tomadas como essenciais e benéficas na maioria dos trabalhos que acabam exprimindo uma espécie de defesa acrítica das ferramentas, de sequências ou jogos didáticos baseados ou inspirados nelas, e nos eventuais efeitos positivos de sua aplicação. Por isso, os autores defendem que o campo deve ser debatido focando-se "[...] a influência das ideologias neoliberal e libertária" (ROSADO; FERREIRA; CARVALHO, 2017, p. 239) majoritariamente vinculadas às políticas educativas e de empresas educacionais que desenvolvem ferramentas educativas utilizando TDIC. Os autores acham que há exagero no foco habilidades/competências e na autorresponsabilização dos alunos para que "resolvam" seus problemas de desigualdade de classe. Na mesma linha, Selwin (2008) defende que seja revista a "responsabilização dos alunos", favorecida pela individualização da aprendizagem. Stephen Ball (2013, p. 147) segue na mesma linha. Enfim, diversos pesquisadores nos advertem a não cair na ilusão de que os meios tecnológicos são supremos, razão pela qual não deveriam ser tomados como princípios da educação.

Como os autores brasileiros (ROSADO; FERREIRA; CARVALHO, 2017), Selwin (2017) também indica que as pesquisas sobre tecnologia e educação são carentes de rigor metodológico; que precisam ultrapassar as abordagens em torno da eficácia e boas práticas, nas quais preponderam as visões simplistas, otimistas ou reacionárias. Assim, defende a emergência de Interfaces da Educ., Paranaíba, v.11, n.32, p. 735 - 763, 2020 
estudos críticos. Neles, a tecnologia na educação deveria ser questionada, desafiando-se então posições dominantes. Para tanto, deveriam sublinhar a luta pela melhor compreensão sobre as questões de poder, controle, conflito e resistência no trato com o uso da tecnologia na educação, reconhecendo-se enfim o papel da tecnologia na perpetuação das desigualdades sociais, com novos formatos de divisão e desvantagem, ensina o autor. Todo esse esforço, por sua vez, trata-se de um exercício construtivo, em que se discutem alternativas para as questões em jogo, a identificação de proposições para os diferentes usos da tecnologia. Resgatam-se a tradição do pensamento da teoria crítica e a defesa da igualdade, da justiça social e da democracia participativa.

Nessa linha ainda, Ferreira, Freitas e Moreira (2018) sinalizam que se associa hoje desenvolvimento à tecnologia avançada: a escolarização deve ser orientada por ela e para a "inovação" (FERREIRA; FREITAS; MOREIRA, 2018, p. 26). A aprendizagem deve ser eficaz, os artefatos digitais estando no centro. O "chão da escola" é assim ignorado, suas "questões sociais e políticas" (p. 28-29) também. Neotecnicismo? Freitas (2014, p. 1087; 2016) considera que sim. A tecnologia é para o autor um instrumento de controle administrativo, pedagógico, do trabalho do professor e sobre o comportamento do aluno, alguém que recebe, memoriza e reproduz informações. Para ele, se reproduz hoje o tecnicismo, marcante no Brasil nas décadas de 1970 e 1980, abordado em trabalhos conhecidos na área (KUENZER; MACHADO, 1986; SAVIANI, 1999).

Os estudos relacionados ao trabalho didático e pedagógico com TDIC deveriam observar e incorporar essas criticas, de modo a superar as estratégias do "solucionismo" (MOROZOV, 2013), frequentes na área; considerar a capacidade da mídia de captar a sociedade, sua história, de produzir realidades outras (CASTELLS, 1999, p. 394). As mídias digitais e suas redes têm mostrado o potencial de produzir narrativas alternativas. $\mathrm{O}$ trabalho especializado e autônomo do professor é essencial na condução dessa produção, de forma que seja crítica e, para além disso, que oriente os discentes à leitura e, também, à elaboração crítica do conhecimento. 
Por óbvio, a disponibilidade de recursos tecnológicos e o aprimoramento das competências tecnológicas não bastam. Inclusive, ensaios mais céticos negam totalmente quaisquer efeitos deles ou de sua utilização pedagógica sobre a aprendizagem (CLARK, 1994). Mas o fato é que a sociedade da informação e a economia do conhecimento afetaram todos os setores da coletividade, marcados pela progressiva descentralização e individualização da natureza da vida no mundo globalizado, interligado e focalizado no conhecimento (SELWIN, 2008).

O desafio atual é trabalhar para que ter, ou não, acesso às ferramentas tecnológicas, seja pelos alunos, seja pelos sistemas de ensino e seus professores, não aumente as desigualdades, já que "[...] nesta era globalizada e centrada na tecnologia, indivíduos, grupos, organizações e países podem ser tão conectados ou isolados, tão beneficiados ou desfavorecidos, quanto antes" (SELWIN, 2008, p. 827-828). Fato a ser trabalhado, uma vez que o autor, concordando com as ideias de Castells (1999), considera que as TDIC têm dupla importância: a expressão ativa e, portanto, mais livre do cidadão; e o favorecimento de mais oportunidades de assimilar os conhecimentos escolares, o acesso às tecnologias que deve ser difundido na sociedade. Ainda assim, um grande esforço a ser feito no que se refere às possibilidades didáticas que se ligam às TDIC continuará sendo uma exigência permanente na área.

As mudanças culturais que a presença das tecnologias engendra devem ser fortemente levadas em conta, como veremos à frente. A escola e os sistemas de ensino dificilmente passarão ao largo do fenômeno tecnológico, de sua apropriação cultural e da relação das pessoas a partir daí. Essa relação, escola e TDIC, mesmo com experiências amplas em investimento e envolvimento, não ocorre sem contradições ou sem problemas que devem ser trabalhados, como se pode aprender a partir da experiência inglesa, relatada a seguir.

No Reino Unido, a partir de 1998, para promover a inclusão social em termos de oportunidades e resultados educacionais, adotaram-se ações em três grandes áreas: a integração contínua das TDIC no currículo nacional; a Interfaces da Educ., Paranaíba, v.11, n.32, p. 735 - 763, 2020 
formação continuada do pessoal docente em termos de uso das tecnologias no ensino; o estímulo e suporte para a produção de software e de conteúdos digitais. Foram realizados esforços para o uso das TDIC visando modernizar a educação no que se refere à ampliação da participação, da personalização, da flexibilidade, da colaboração, do desenvolvimento do pessoal e das parcerias e, mais recentemente, para apresentação de relatórios em tempo real, on-line, entre as escolas e os pais, para informá-los sobre as aulas e o desempenho e comportamento dos alunos (SELWIN, 2008).

Como resultado desse conjunto de ações, o autor destaca três aspectos: a quebra das barreiras no uso das TDIC em todas, ou quase todas, as instituições educacionais; professores tecnicamente mais confiantes e mais propensos a usá-las em sua prática de ensino; e a criação de uma vasta infraestrutura organizacional dedicada a melhorar sua utilização em todo sistema educacional - como órgãos de mediação oficial, empresas, organizações privadas e de caridade. Essas mudanças positivas em diversas esferas da vida escolar, da relação ensino-aprendizagem, do trabalho docente, não tiveram, pelo menos naquele momento, um grande impacto nos resultados e nas oportunidades educacionais naquele país, concluiu Selwin (2008).

Vemos a partir da experiência inglesa que associar o uso da tecnologia à produção de melhores resultados escolares tem seus limites se considerada tão somente esta dimensão. Nesse sentido, as críticas de Clark (1994), para quem as tecnologias não têm esse poder de educar, estariam certas? Deveriamos abandonar tudo e nos focar no treino e na memorização? As modificações favorecidas pelas TDIC seriam irrelevantes?

Os trabalhos de Selwin (2008; 2016) e de Feenberg (2003) não são conduzidos de modo que as questões anteriormente colocadas possam receber respostas positivas. Andrew Feenberg (2003) propõe, assim, uma leitura filosófica da questão em três temas: sobre o determinismo tecnológico; sobre o instrumentalismo; sobre o substancialismo. Dessa forma, indica inicialmente um olhar crítico sobre o que apresenta como histórico determinismo tecnológico, em que a tecnologia se apresentaria Interfaces da Educ., Paranaíba, v.11, n.32, p. 735 - 763, 2020 
como neutra, essencial, moldada pela eficiência; fábrica e produto que se buscam na sociedade contemporânea. Em seguida, chama a atenção para a assimilação das tecnologias sob certa neutralidade, já que elas seriam aceitas como ferramentas e perfeitamente dominadas pelo homem, que assim agiria para satisfazer suas necessidades, em uma visão então instrumentalista, o que não parece corresponder aos fatos, defende o autor. De modo geral, quando se faz menção ao uso das tecnologias no âmbito escolar, essas visões, deterministas e instrumentalistas, são predominantes. Enfim, como mostra Milhano (2010), Feenberg orienta-se para a visão substancialista da tecnologia, aí tomada como "[...] uma ameaça ao cunho humanístico da sociedade moderna" (MILHANO, 2010 p. 26), para advertir sobre o controle social a que pode servir. O artigo de Freitas (2014) converge sobretudo para essa linha de crítica. Não negligenciável, alerta para a entrada da tecnologia na administração dos sistemas educativos, na escola, na formação inicial e continuada de professores, no planejamento e exercício docente, na avaliação da aprendizagem, comparação, medição e eventual punição ou premiação por resultados padronizados pela administração central.

Esses valores deveriam ser enriquecidos por uma Teoria Crítica da Tecnologia, capaz de reintegrar valores esquecidos e desprezados pela maioria, propõe Feenberg (2015), apresentando, assim, uma reinvenção do referencial técnico da vida moderna (FEENBERG, 2015, p. 279). Partindo dos argumentos avançados do construtivismo sociológico da tecnologia, entende-se que, ao longo do processo de criação das várias tecnologias, surgem diversas hipóteses de design concorrentes que podem alcançar os mesmos objetivos com o mesmo nível de eficiência. A opção por um design é decorrente da compatibilidade com o meio social para o qual se destina. Nesse sentido, são reconhecidas as possibilidades de intervenção no mundo social com o desenvolvimento da tecnologia. Por esta razão, a partir das estruturas, a tecnologia mostra-se tendenciosa, já que se encontra vocacionada para o cumprimento dos desejos e interesses das classes sociais dominantes. Haveria nesse contexto espaço para uma tecnologia alternativa? Interfaces da Educ., Paranaíba, v.11, n.32, p. 735 - 763, 2020 
Feenberg afirma que os interesses sociais são embutidos na tecnologia e, portanto, podem ser transformados para libertar o mundo social do controle exercido pelo poder sociopolítico. Ao se reconhecer que dentro do contexto de uma sociedade estratificada as classes sociais dominantes possuem mais influência sobre o design da tecnologia do que as classes sociais subordinadas, é possivel considerar que a tecnologia está sujeita a influências relativas a interesses sociais, como do paradigma da eficiência. Isso em vista, cabe considerar que no campo em questão seja valorizada a tradição humanista, o equilíbrio das liberdades individuais (autonomia individual) e o desenvolvimento máximo das capacidades dos seres humanos (FEENBERG, 2006, apud LOPES, 2015, p. 139). Tal desenvolvimento das capacidades pode ser expresso por meio de luta por mais liberdade, mais igualdade; por meio da valorização da responsabilidade moral, da individualidade e da criatividade, de modo que "[...] os atores subordinados também possam ter voz regulativa na dinâmica tecnológica” (LOPES, 2015, p. 132).

\section{As TDIC na educação: efeitos favoráveis à aprendizagem?}

O exposto até aqui nos dá elementos suficientes para responder uma das questões postas como linha diretiva deste ensaio: não, as críticas não se esgotam em si, mesmo no campo das TDIC. Aquelas que aqui referimos parecem essenciais para se entender o tema, sua abordagem pela sociedade, pelos sistemas de ensino, pela escola e seus atores. Além disso, fica clara a visão dos autores sobre o campo, sobre o que deve ser aprimorado: mais formação do professor, do aluno, mais acesso à cultura. A opção é pela supremacia do humano, sua capacidade intelectual, criadora, crítica e, portanto, a compreensão e apropriação dos fenômenos tecnológicos, mais do que a assimilação, parece ser uma linha irrefutável.

Assim, o fenômeno tecnológico e os aparelhos a ele vinculados podem ter, efetivamente, interesse para o trabalho pedagógico. Já citamos pesquisa que mostra a forte presença de celulares "inteligentes" em escolas públicas Interfaces da Educ., Paranaíba, v.11, n.32, p. 735 - 763, 2020 
brasileiras (SALATINO; BUENO, 2015). O raro uso pedagógico do digital revela, para além dos problemas estruturais e materiais das escolas, uma dificuldade dos professores, relativamente alheios ao movimento das TDIC (SOARES-LEITE; NASCIMENTO-RIBEIRO, 2012). Mas uma aprendizagem eficaz requer a compreensão de seus mecanismos pelo professor, e que ele construa com os alunos sistemas de organização do pensamento. Não se pode conceber que um professor proponha aos seus alunos que classifiquem as frases de um texto qualquer em classes gramaticais sem que em etapas anteriores eles tenham aprendido a classificar, simplesmente. Por essa razão, o professor é fundamental para nos orientar ao conhecimento que queremos desenvolver; no mundo digital, muito mais aberto, essa orientação é fundamental. A didática com TDIC exige, portanto, amplo saber técnico e pedagógico, mas também a compreensão dos processos psicológicos por meio dos quais são organizados o nosso pensamento. Falamos aqui do princípio de mediação ou de apoio do professor ao aluno, como preconizou Bruner (1983). Essa mediação ou apoio do professor deve proporcionar ao aluno "[...] a capacidade de resolver um problema, de ser capaz de fazer corretamente uma atividade ou de atingir um objetivo que, sem a assistência docente, não seria alcançado" "(BRUNER, 1983, p. 263).

$\mathrm{O}$ princípio exposto anteriormente serve perfeitamente para enriquecer as possibilidades pedagógicas em geral, mas também aquelas relativas às TDIC que, por si só, como demonstrou Selwin (2008), não são produtoras de qualidade educativa. Assim, o que mais importa é o modo como é operada essa tecnologia. O professor aqui tem grande destaque. A didática construída, a forma como é mobilizada, é mais importante do que o celular, do que o tablet, do que o computador: é a maneira como se aplica a tecnologia que será determinante para eventual influência na aprendizagem (RUSSEL, 1999). É possivel organizar os alunos em redes de interaprendizagem. Ela combinaria aprendizagem individual, coletiva e,

\footnotetext{
${ }^{1}$ Todas as citações extraídas de trabalhos estrangeiros foram traduzidas pelos autores deste artigo.
} 
sobretudo, colaborativa, que seria enriquecida pela mediação docente. O professor estimula a pesquisa, a busca por respostas. Oferece suporte, disponibiliza elementos-chave, dá apoio, medeia, porém propicia espaço para que o aluno busque a resposta e para que a justifique. Quais desafios na organização do ensino os professores enfrentam diante das tecnologias?

O estudo de Schuhmacher et al. (2017) destaca três obstáculos: o estrutural, em relação a equipamentos e acesso à internet; os epistemológicos, pertencentes à própria natureza do conhecimento sobre tecnologias; e os didáticos, relacionados às estratégias de ensino. Para Coutinho (2008, p. 118-119), a hostilidade dos professores em face da utilização das tecnologias de que as veem como simples auxiliares didáticos; se relaciona com suas dificuldades de adaptarem seus estilos de ensino às inovações; enfim, justifica-se pelo medo de serem substituídos, etc. As atitudes positivas dos professores diante de medias podem ser atribuídas ao que se designa como isomorfismo, isto é, a adoção, pelas novas gerações de professores, dos métodos utilizados no seu processo de aprendizagem, o que não se configura necessariamente como melhor qualidade do ensino. De certo, há ainda um grande vazio didático-pedagógico, que conclama os pesquisadores a aprofundar estudos sobre a efetividade do digital na aprendizagem.

\section{O que dizem os estudos?}

Sobre essa efetividade de resultados para a aprendizagem discente na mobilização das TDIC na educação, os estudos não são unânimes. Oscilam entre a defesa e a relativização da eficácia das TDIC, como mostra o relatório da Unesco (PELGRUM; LAW, 2003). Essa oscilação aparece às vezes no mesmo trabalho, caso do artigo de Pouts-Lajus (2001), onde, por um lado, o autor mostra que para alguns as telas podem ser um fator de bloqueio entre o aluno e o conteúdo, com eventuais efeitos negativos no plano psicológico, e, por outro lado, baseando-se em depoimentos de professores e pais de alunos, o autor reconhece que as TDIC podem ter uma utilização bemInterfaces da Educ., Paranaíba, v.11, n.32, p. 735 - 763, 2020 
sucedida no processo de ensino-aprendizagem. Apesar disso, o próprio Pouts-Lajus (2001) indica que é preciso que mais estudos sejam feitos, com método científico rigoroso, de maneira que sejam superadas as abordagens em torno apenas de testemunhos de pais, alunos e professores, ideia com a qual concorda Cédric Fluckiger (2017, p. 121). Esses estudos fazem falta, por exemplo, para deixar claro em quais situações usar TDIC é interessante e em quais ele é menos eficaz.

Knoerr (2005, p. 59), por exemplo, mostra que promessa e realidade devem convergir em alguma medida, caso contrário é praticamente certo o fracasso na utilização de TDIC. Os tecnocratas imaginam um aluno que aprende tudo com mais qualidade, menos dificuldade, e professores mais envolvidos e mais populares à vista de seus alunos. A realidade não sendo de fato esta, a decepção tem grandes chances de ganhar terreno, explica a autora. Então, mais estudos e conhecer criticamente uma prática pedagógica tomando TDIC por recurso são essenciais para que as experiências tenham mais chances de sucesso.

Outra advertência de Knoerr (2005) refere-se à seleção de práticas de ensino utilizadas com TDIC, uma vez que, em suas experiências e estudos, verificou que "[...] práticas mais centradas no professor (saber vertical em relação ao aluno) e unilaterais (onde não se incorpora a relação entre professor e aluno e entre discentes)" (KNOERR, 2005, p. 59) se beneficiam menos do que pedagogias ativas, do tipo construtivista, por exemplo, em relação a mais qualidade de aprendizagem para os alunos. Enfim, para a autora, as abordagens construtivistas funcionariam melhor nesse caso de mobilização de TDIC. Elas, as abordagens construtivistas, nos parecem, por base e princípio, mais de acordo com as críticas trazidas ao longo do trabalho e, para além disso, com as preconizações de Feenberg e seus comentadores aqui referidos.

Vejamos, então. Estamos falando de certas práticas de ensino em relação às TDIC. São as práticas que se beneficiam das TDIC, e não o contrário. Um professor que conhece profundamente as tecnologias, os conteúdos a ensinar e, ainda, as práticas de ensino relativas aos conteúdos Interfaces da Educ., Paranaíba, v.11, n.32, p. 735 - 763, 2020 
que vai ensinar (SHULMAN, 1986) é quem poderá justamente mobilizar os recursos tecnológicos em favor de sua ação de ensinar, e não o contrário. Sobre isso, Villemonteix e Beziat (2013 apud FLUCKIGER, 2017, p. 127) mostram que o uso de quadros interativos (ou lousa digital) acaba por "reforçar formas clássicas de ensino". Por qual razão? Porque o quadro interativo oferece recursos - utilização de links, ferramentas de pesquisa, documentos sonoros, audiovisuais - na própria lousa, o que favorece ainda mais a concentração do professor em relação ao recurso e, assim, ao reforço de práticas de ensino clássicas, ditas tradicionais. Muitos se perdem nas amplas bases de dados que as empresas fabricantes dos quadros interativos oferecem e acabam voltando a pautar suas aulas pelo livro didático, ainda que agora na sua versão digital (FLUCKIGER, 2017, p. 127-128). Enfim, conta mais o perfil do professor, daquele que tem uma profunda cultura digital (VILLEMONTEIX; KHANEBOUBI, 2013), do que o recurso tecnológico em si, para que práticas inovadoras, criativas, sejam praticadas, desenvolvidas e testadas. O recurso sozinho, como vimos, pode até reforçar gestos professorais mais clássicos, ditos tradicionais.

Para a pesquisadora Hélène Knoerr (2005), as metodologias didáticas mais adequadas na associação das TDIC à educação envolvem: 1) a aprendizagem por resolução de problemas, o professor devendo ter absoluta clareza das tarefas e situações de ensino que mobilizará; 2) a aprendizagem cooperativa, ensino e aprendizagem devendo estar ancorados em ampla colaboração com o professor e o aluno; 3) a pedagogia por projetos, na busca por desenvolvimento pleno do aluno e de sua cidadania. Isso tudo deve ser posto em relação ao que preconizamos antes: o interesse, a formação, a cultura digital do professor. Quer dizer, não basta colocar um tablet, um celular inteligente, um quadro Interativo à disposição para que as práticas pedagógicas citadas por Knoerr (2005) apareçam automaticamente. Isso posto - professor e TDIC associados -, podemos no plano didático e pedagógico observar, segundo seus estudos (KNOERR, 2005), efeitos positivos na motivação para a aprendizagem. 
Para alunos com dificuldades de aprendizagem, muitas práticas de diferenciação pedagógicas podem ser mobilizadas: jogos didáticopedagógicos, do tipo serious games (videogames sérios), por exemplo, têm bons efeitos, na aprendizagem da leitura e escrita. O fato de mobilizar e gerenciar informações, fazer e rever escolhas, testar possibilidades, manipular imagens, às vezes tocando-se diretamente em telas sensiveis ao toque, tem efeito na memorização de informações, mas também na reflexão. Do ponto de vista da aprendizagem, esse recurso pedagógico se justifica, já que assimilamos e aprendemos mais quando estamos em ação, ou seja, cerca de $90 \%$ contra "[...] $10 \%$ do que lemos, $20 \%$ do que escutamos, $30 \%$ do que vemos, $50 \%$ do que vemos e escutamos e $80 \%$ do que dizemos" (KNOERR, 2005, p. 59). Obviamente, e como demonstra Mansouri (2019), o processo de concepção, a roteirização desses jogos, o design dos jogos, devem contar com professores que conheçam profundamente a didática e as práticas relativas aos conteúdos que espera ensinar. Além disso, deve ser priorizada uma abordagem integrada entre as partes lúdica e pedagógica dos jogos. Quer dizer que o pedagógico, os gestos que serão necessários para se aprender determinado conteúdo são planejados em detalhe, lado a lado com os aspectos lúdicos (MANSOURI, 2019, p. 207), quando o mais corrente hoje em dia, indica o pesquisador, é que se faz um jogo para depois pensar em temas que podem ser trabalhados a partir dele. Se um jogo pensado para a leitura e escrita é concebido ao lado ou por um professor especialista em metodologias de ensino na área, há mais chance de que nesse jogo sejam escolhidos gestos que favoreçam, por exemplo, a aprendizagem da relação grafema e fonema. Um toque na tela e ouviria o som da letra que se apresenta; ao escutar um determinado som, indicaria sua grafia; trabalho mais tradicional de alfabetização, que pode ser feito sozinho ou em pequenos grupos, utilizando-se tablets, celulares inteligentes, computadores, projeções, áudios e impressos. Podemos também propor a associação entre sons da fala - sílabas, palavras, frases - a cenas, imagens de um jogo, com interações do aluno com o computador e/ou em rede com colegas: jogando 
juntos podem alcançar novas hipóteses de escrita, tirar dúvidas, se quisermos pensar em uma perspectiva construtivista de alfabetização.

Ainda na linha da diferenciação do ensino e de suas práticas na direção de alunos com dificuldades de aprendizagem, Chouinard (1998) defende que as TDIC sejam tomadas como possibilidade, uma vez que para ele: 1) as TDIC se adaptam ao tempo do aluno com dificuldades, às suas necessidades pedagógicas e à necessidade de atenção individualizada; 2) as tecnologias oferecem excelentes ferramentas para captar, registrar e trabalhar avanços e dificuldades do aluno. Nesse caso, os jogos em vídeo sérios, em virtude da programação que recebem, podem registrar erros mais recorrentes, quando pretendem passar informações, para que sejam corrigidos em futuras edições; 3) as TDIC são apropriadas ao ensino estratégico, acompanhamento do potencial intelectual e da inteligência do aluno. No caso de jogos mais interativos, que permitem a intervenção, sinalização de problemas pelos alunos jogadores, podem registrar essas criações e os limites que eventualmente uma fase do jogo apresenta à manifestação da criatividade discente, podendo indicar uma aprendizagem ou um bloqueio. A implicação do professor é obviamente fundamental nesse processo, devendo observar mais, orientar o aluno de forma pedagógica e ajudá-lo na captação do conhecimento e superação das dificuldades.

Para Chouinard (1998), alunos com deficiência também podem desfrutar do emprego de certas TDIC, já que são uma importante fonte de informação, mas também de comunicação. Esse é o caso de alunos surdos. Dalle (2015) lembra que alunos surdos e que conhecem a lingua de sinais (francesa em seu trabalho) se comunicam bem entre si. Porém, na escola ou na vida fora dela, esses alunos precisam se comunicar com não surdos. Para ter acesso à informação e à formação devem explorar outras formas de comunicação que extrapolam a lingua de sinais, como, por exemplo, a escrita, o que também contribui para que obtenham mais acesso ao mercado de trabalho. Desse modo, sua participação no mundo atual pressupõe participação e integração à cultura geral. 
Para Dalle (2015, p. 4-8), essa participação tem sido facilitada pela sofisticação de programas de computador capazes de traduzir a escrita convencional em língua de sinais. Esses programas, como o Photosigne, por exemplo, geram uma representação gráfica da lingua de sinais. A "escrita" da lingua de sinais, nesse caso em francês, vai sendo aos poucos adicionada em textos convencionais. Assim, os alunos surdos vão se familiarizando com a escrita convencional, que lhes será importante na vida profissional, de estudos, de manifestações políticas. Nesse caso, as TDIC ampliam a possibilidade de comunicação e a formação de elos sociais, contribuindo também para desenvolvimento da escrita e da leitura de alunos surdos, elementos importantes para melhor integração social deles, entende a autora.

O caso descrito é um bom exemplo de associação entre TDIC e educação. Porém, sem o professor e demais profissionais da educação envolvidos, sem uma forte cultura digital da parte desses profissionais, o programa Photosigne não poderia ter sido criado, aplicado, avaliado e aperfeiçoado a contento. Quer dizer, o planejamento, a construção e a execução do projeto didático dependeram primeiro dos atores educacionais e de seus talentos na mobilização pedagógica das TDIC. Enfim, cultura digital e a implicação dos profissionais envolvidos foram essenciais para o desenvolvimento e execução desse projeto.

A forma como as TDIC são utilizadas dependem também do professor e de como a equipe de profissionais da educação as mobilizam. Isso tem a ver com a cultura digital de quem os utiliza, com seus métodos pedagógicos, com suas estratégias didáticas. Por exemplo, o Massive Open Online Course (MOOCS) pode ser empregado no ensino transmissivo. Os nomeados xMOOC (FLUCKIGER, 2017, p. 126), baseados em videoaulas, podem ser úteis tanto para cursos pontuais quanto para ensinar a criação de jogos de videogame sérios (UNIVERSITÉ DE MONTPELIER, 2020); já os chamados cMOOC, podem ser utilizados para um formato mais integrador, que priorizam a interatividade entre os alunos - que "[...] envolveria diversos aspectos do 
ensino: a natureza do conhecimento, o papel dos alunos e do professor, além dos modos de avaliação" (FLUCKIGER, 2017, p. 126).

Os cMOOC têm se revelado uma ferramenta de inovação pedagógica. Essa TDIC, planejada dessa forma, pode auxiliar o professor a evitar problemas no uso da internet, por exemplo, com alunos dispersos. No cMOOC são mais comuns, e se desenvolvem progressivamente, esquemas que se servem objetivamente da possibilidade do relatório do aluno em relação à alguma atividade, aprendizagem ou dificuldade; da argumentação, da exposição de suas aquisições em niveis mais avançados de estudos, com relatórios escritos e orais mais elaborados, mais exigentes em virtude do nível de ensino. É comum que ao final de um módulo tenhamos que responder a algumas questões antes de avançar ao seguinte, em uma espécie de relatório objetivo de aprendizagem. Plataformas do mesmo tipo, como a "khan academy", direcionam automaticamente para outras aulas quando não respondemos corretamente a determinada questão. Os cMOOCs mais contemporâneos, que ultrapassaram a perspectiva transmissiva (FLUCKIGER, 2017, p. 130), apresentam inovações didático-pedagógicas importantes. Além do que já apontamos, a classe/aula invertida parece ser a possibilidade mais rica, pelo desenvolvimento mais palpável referente a inovações pedagógicas. Os alunos podem assistir aos cursos em plataformas on-line, e tirar suas dúvidas na sala de aula, quando sabemos que o funcionamento clássico da sala de aula é o inverso. Felizmente, e isso nos parece importante, a sociologia da utilização desses recursos pelos alunos, conforme Jouet (2000), numa perspectiva crítica, elucidando os modos como se apropriam deles, ajudam pesquisadores em educação, pedagogos, professores buscar o aprimoramento desses e de outros dispositivos.

Os recursos tecnológicos estão cada vez mais presentes, mais desenvolvidos e, para além da questão de inovação tecnológica, a preocupação deve se centrar nos aspectos didático-pedagógicos inovadores que podem ser vislumbrados a partir daí. Para Cédric Fluckiger (2017), é necessário que abandonemos o "[...] determinismo tecnológico que induz à análise de cada inovação tecnológica [e] abandonar a falsa questão da Interfaces da Educ., Paranaíba, v.11, n.32, p. 735 - 763, 2020 
eficácia" (FLUCKIGER, 2017, p. 131), em favor das lógicas pedagógicas (inovações didáticas) que se podem produzir e dos estudos sociológicos sobre a utilização das tecnologias e inovações, de modo que, como dito anteriormente, seja reorientada e assimilada à prática pedagógica já estabelecida.

Agora, mais do que nunca, os bancos de dados com recursos pedagógicos digitais estão em crescimento. Muitos professores recorrem a eles, bem como às diversas bibliotecas virtuais e aos blogs, páginas de redes sociais que compartilham experiências pedagógicas, inovações ou relatos sobre didáticas distintas. E são eles, os professores - mais uma vez constatamos -, com seus saberes da experiência, que poderão atribuir a esses recursos mais significados; conhecendo-os, poderão inovar pedagogicamente. Os tablets, os telefones inteligentes, os Quadros Interativos, os MOOCs devem ser estudados dentro de um campo de possibilidades de didáticas inovadoras, com aprofundamento de pedagogias ativas. As classes/aulas invertidas, que obviamente têm seus limites e contradições (GUILBAULT; VIAU-GUAY, 2017), mas também possibilidades interessantes, entram nesse campo de inovações em construção de didáticas e pedagogias ativas, com repercussões em termos de aprendizagem para os alunos e para aqueles que necessitam de recursos didáticos específicos, individualizados. Mas, por óbvio, e felizmente, essa não é a única possibilidade existente a ser explorada. Os trabalhos aqui referidos deixam abertas linhas de estudo e de experimentação didática que poderão ser trilhadas por nós e demais pesquisadores em educação e professores interessados no tema TDIC-educação e demais questões aqui levantadas.

\section{Considerações finais}

Chegando às considerações finais deste artigo, podemos fazer algumas observações. Como fenômeno forte e presente na sociedade brasileira e mundial as TDIC devem ser tomadas de maneira crítica, para que, em primeiro lugar, seja (re)estruturada e regulada uma plataforma para a Interfaces da Educ., Paranaíba, v.11, n.32, p. 735 - 763, 2020 
manifestação da sociedade, sobretudo daqueles que não têm voz reguladora; em segundo lugar, para que as TDIC sejam usadas como ferramentas educacionais que contribuam para o movimento de participação, do diálogo, do debate, da construção coletiva do conhecimento e dos caminhos para a aprendizagem. Enfim, para que contribuam para práticas pedagógicas inclusivas. É preciso que se experimente os efeitos positivos das TDIC na educação dos brasileiros e que se vença os desafios apontados ao longo deste trabalho, de maneira que o uso das TDIC não se legitime como fator de desigualdades. O que argumentamos é sobre a necessidade de superação das visões universalistas e naturalizadas da tecnologia, como defendem os autores que deram base para este ensaio. A problematização do uso das TDIC é fundamental e, nessa linha, atrela-se aos ideários democráticos e humanistas.

Essa visão mais crítica pressupõe, conforme Feenberg (2003), a superação do determinismo tecnológico, que preconiza neutralidade e essencialidade da tecnologia. Criadas pelos homens, as tecnologias podem ajuda-los a transmitir seus valores, interesses e pautas, a impor seus designers tecnológicos, ou seja, elas não são neutras. Um Teoria Crítica da Tecnologia, conforme Feenberg (2003), preconizaria, ainda, a superação de visão instrumentalista, como se o homem dominasse e tirasse apenas proveito da tecnologia; por fim, seria questão de superação de sua visão substancialista, como se, naturalizada em nossas vidas, a tecnologia pudesse modelar e orientar nossas relações sociais sem prejuízos pessoais e também nas relações profissionais.

Esses principios nos parecem centrais na busca por uma relação crítica entre TDIC e educação. Evidentemente, enganoso seria imaginarmos que as TDIC por si só poderiam romper com o ciclo de desigualdades educacionais e promover aprendizagem com mais qualidade e eficácia. Não podem. Os vários estudos e posicionamento citados ao longo deste texto mostram isso. Felizmente, eles também demonstram que a associação das TDIC às lógicas didático-pedagógicas, mais do que à eficiência desse ou daquele aparelho ou ferramenta tecnológicas/digital, pode ter efeitos Interfaces da Educ., Paranaíba, v.11, n.32, p. 735 - 763, 2020 
positivos na aprendizagem dos alunos, sobretudo para sua consciência social e formação humanística. Os princípios dados por Feenberg (2003) nos parecem convergentes com esses objetivos em relação ao alunos e às suas formações. Uma experiência positiva em relação às TDIC, tanto para o professor quanto para o aluno, pode aprofundar o interesse crítico sobre seus processos e seus efeitos na sociedade, bem como a compreensão crítica desses atores escolares sobre o meio social em que vivem e os poderes politicos, econômicos e culturais que exercem influência sobre ele.

Estudos futuros sobre o uso didático-pedagógico das TDIC, além de considerar os apontamentos críticos abordados nesse artigo, deveriam se concentrar nos fazeres docentes, nas suas ações de ensinar, pelas seguintes razões : 1) porque há essa preocupação quase permanente relativa à liberdade que é dada aos alunos e eventual má utilização dos recursos digitais, diriamos que é preciso desconfiar dos métodos que utilizam e dos conhecimentos que afirmam ter encontrado/adquirido. Há, claro, uma distância entre o que os alunos dizem fazer e o que fazem de fato. Podemos pedir que escrevam, que expliquem, que falem sobre seus novos conhecimentos, que façam um esforço de aplicá-los a certa realidade: esse procedimento pode ajudar ao docente a verificar se o aluno está apenas repetindo aquilo que ele acha que o seu professor espera ouvir, ou se apreendeu e consegue, portanto, generalizar a informação: a criatividade, o novo, brota a partir daí. Em trabalhos que envolvam a utilização de motores de pesquisa (Google, Ask etc.), de sites de internet, de bibliotecas virtuais, de redes sociais, a mediação docente é essencial. Algumas ferramentas presentes nos MOOC ajudam a resolver parte desses problemas; 2) em face da preocupação de que essa autonomia discente se transforme num prejuízo em termos de solidez e eficácia de sua aprendizagem, é importante no emprego da TDIC e de suas ferramentas digitais que os procedimentos para sua utilização sejam claramente estabelecidos. Os alunos devem saber o que deles se espera: é o bom contrato didático (BROSSEAU, 1982) no qual o professor e o aluno sabem quais papéis desempenham na relação pedagógica estabelecida, clareza fundamental para que a aprendizagem Interfaces da Educ., Paranaíba, v.11, n.32, p. 735 - 763, 2020 
ocorra. Ou seja, usar TDIC não significa deixar o aluno solto diante dos jogos pedagógicos, redes sociais, internet para fazer o que desejar. O aluno tem na relação pedagógica que se estabelece uma missão: buscar a informação, a aprendizagem, etc.; e o professor tem a sua: oferecer recursos, dicas, fazer analogias, dar exemplos, indicar metodologias de pesquisa e de estudo, de modo que o aluno avance da maneira mais autônoma possível na construção crítica do conhecimento.

De certa maneira, os procedimentos, não exaustivos, apresentados acima se filiam corretamente ao imperativo didático de se criar esquemas para a aprendizagem e abstração que podem ser ainda mais essencial do que poderíamos imaginar diante da mobilização de TDIC em nossos sistemas de ensino, nas escolas, nas aulas, de forma isolada ou em bloco, por meio de sequências didáticas, por exemplo. Qualquer que sejam as vias, o professor não pode ser submetido à máquina, à tecnologia, às TDIC. Essas últimas, por sua vez, fortemente integradas à prática social, não têm como ser ignoradas, seja pelo professor seja pelos sistemas de ensino, ou pelas escolas.

O que preconiza Feenberg (2010), nos parece, portanto, deveras importante e deve ser levado em conta, isto é, dar mais voz aos subordinados à tecnologia (LOPES, 2015) é fundamental. Em que pesem eventuais limites metodológicos ou epistemológicos, os exemplos dados na segunda seção desse texto vão nessa direção, mostrando que é preciso implementar práticas que valorizem o trabalho pedagógico aberto ao diálogo entre professores e alunos e a construção coletiva dos caminhos para a melhoria da aprendizagem. Os professores têm um papel central nisso, que é contribuir para a inversão do paradigma de subordinação à tecnologia e sua inovação irracional como princípio social e didático-pedagógico.

As TDIC comportam diversos recursos para a mobilização didáticopedagógica pelos professores, pedagogos e planejadores educacionais. Como parte da cultura atual, inevitavelmente, as TDIC farão parte da vida dos alunos. Então, mais formação em torno da questão das TDIC parece essencial, tanto para eles quanto para os professores. No caso dos alunos, Interfaces da Educ., Paranaíba, v.11, n.32, p. 735 - 763, 2020 
para entenderem como as TDIC são integradas na sociedade; para os professores, conforme Shulman (1986), para que possam fazer uso das TDIC de forma crítica e proveitosa em termos de inovações pedagógicas, em prol de ensino e aprendizagem com qualidade.

Os desafios brasileiros são, portanto, imensos. Primeiro, porque a informática de maneira geral precisa ser mais e melhor estudada e entendida a respeito da sua contribuição para a educação - ela própria carecendo do desenvolvimento de um campo didático-pedagógico para seu ensino (FLUCKIGER, 2019). Além disso, no caso brasileiro, a profunda desigualdade social nos cobra criatividade em produzir práticas didáticopedagógicas inovadoras, em um lugar onde ela é fundamental, para que mais alunos aprendam com a melhor qualidade possivel.

Em outro trabalho (SANTOS; FERREIRA, 2020), pensando sobre os problemas da educação brasileira e dos desafios didático-pedagógicos colocados, levantamos linhas de discussões que seriam peculiares em uma didática multidimensional, na acepção de Franco e Pimenta (2016), com as TDIC. A concepção de didática multidimensional nos parece essencial, tendo em vista a realidade de diferenças sociais e educativas no Brasil; levantamos, então, os desafios a serem enfrentados - financiamento das escolas, equipamentos, formação de professores e de alunos - e propusemos que mais estudos fossem realizados no campo das práticas didático-pedagógicas com TDIC. Nessa linha, são expressivas as possibilidades de pesquisa para todos os pesquisadores brasileiros do campo em questão.

\section{Referências}

BALL, S. Aprendizagem ao longo da vida, subjetividade e a sociedade totalmente pedagogizada. Educação, Porto Alegre, v. 36, n. 2, p. 144-155, maio/ago. 2013. Disponivel em: $<$ http://revistaseletronicas.pucrs.br/ojs/index.php/faced/article/view/128 86/9446>. Acesso em: 15 jan. 2020. 
BROUSSEAU, G. Ingénierie didactique. D'un problème à l'étude à priori d'une situation didactique. In : Deuxième école d'été de didactique des mathématiques. Paris : Olivet, 1982.

BRUNER, J.S. Le développement de l'enfant : savoir faire, savoir dire. Paris : PUF, 1983.

CASTELlS, M. A sociedade em rede. São Paulo: Paz e Terra, 1999.

CHOUINARD, J. Permettre aux élèves de l'adaptation scolaire de s'approprier les nouvelles technologies de l'information et de la communication. Montréal : Cemis, 1998.

CLARK, R. Media will never influence learning. ETR\&D, vol. 42, n. 2, p. 2129, 1994. Disponivel em: <https://www.jstor.org/stable/30218684>. Acesso em: 09 fev. 2020.

COUTINHO, C. P. A influência das teorias cognitivas na investigação em Tecnologia Educativa: pressupostos teóricos e metodológicos, expectativas e resultados. Rev. Port. Educ., Minho, vol. 21, n. 1, p. 101-127, 2008. Disponivel em: <https://revistas.rcaap.pt/rpe/article/view/13921/10509> Acesso em: 13 jan. 2020.

DALLE, P. TIC pour l'intégration des sourds par la langue des signes. Terminal, Paris, n. 116, p. 1-15, 2015. Disponivel em: <http:// journals.openedition.org/terminal/613>. Acesso em 15 mar. 2020.

FEENBERG, A. O que é a filosofia da tecnologia? Conferência pronunciada para os estudantes universitários de Komaba, jun. 2003. Disponivel em: <http://www.sfu.ca/ andrewf/oquee.htm>. Acesso em: 02 fev. de 2020.

Replies to critics. In: VEAK, T. J. (Ed.). Democratizing technology: Andrew Feenberg's critical theory of technology. Albany: State University of New York Press, 2006, p. 175-210.

Simondon e o construtivismo: uma contribuição recursiva à teoria da concretização, Scientiæe Studia, 13(2), p. 263-281, 2015. Disponivel em: <https://doi.org/10.1590/S1678-31662015000200002>. Acesso em: 05 mar. 2020.

Between reason and experience: essays in technology and modernity. Cambridge: MIT Press, 2010.

FERREIRA, G. M. S., FREITAS, R. C., MOREIRA, L. C. P. Inovação, TIC e docência: práticas e concepções de professores em uma IES privada. Rev. Inter. Educ. Sup. Campinas, v. 4, n. 1, p. 25-51, jan./abr. 2018. Disponivel em: <https://doi.org/10.22348/riesup.v4i1.8650880>. Acesso em : 07 jan. 2020 . 
FLUCKIGER, C. Innovations numériques et innovations pédagogiques à l'école. Recherches, n. 66, p. 119-134, set. 2017. Disponivel em: $<$ http://www.revue-recherches.fr/wp-content/uploads/2019/05/119134_R66_Fluckiger.pdf>. Acesso em: 13 jan. 2020.

. Une approche didactique de l'informatique scolaire. Rennes : Presses Universitaire de Rennes, 2019.

FRANCO, M. A. S.; PIMENTA, S. G. Didática Multidimensional: por uma sistematização conceitual. Educ. Soc., Campinas, v. 37, n. 135, p. 53953, jun. 2016. Disponivel em: <https://doi.org/10.1590/ES010173302016136048>. Acesso em: 18 dez. 2019.

FREITAS, L. C. Os reformadores empresariais da educação e a disputa pelo controle do processo pedagógico na escola. Educ. Soc., Campinas, v. 35, n. 129, p. 1085-1114, dec. 2014.2 Disponivel em: $<$ http://dx.doi.org/10.1590/ES0101-73302014143817>. Acesso em: 29 jun. 2019.

. Tecnicismo: ele está de volta. Avaliação educacional, Blog do Freitas, Campinas, 20 ago. 2016. Disponivel em: $<$ https://avaliacaoeducacional.com/2016/08/26/tecnicismo-ele-esta-devolta/>. Acesso em: 20 nov. 2019.

GIROUX, P.; COULOMBE, S.; CODY, N.; GAUDREAULT, S. L'utilisation de tablettes numériques dans des classes de troisième secondaire : Retombées, difficultés, exigences et besoins de formation émergents. Revue Sticef, Le Mans, v. 20, 2013. Disponivel em: <http://sticef.univlemans.fr/num/vol2013/07-giroux-cren/sticef_2013_NS_giroux_07.htm>. Acesso em: 10 mar. 2020.

GUILBAULT, M.; VIAU-GUAY, A. La classe inversée comme approche pédagogique en enseignement supérieur : état des connaissances scientifiques et recommandations, Ripes, Sherbrooke, v.33, n.1, 2017. Disponivel em: <http://ripes.revues.org/1193>. Acesso em: 10 mar. 2020.

HAMON, D.; VILLEMONTEIX, F. Le rapport des élèves et des enseignants aux tablettes numériques à l'école primaire : vers une évolution de la forme scolaire ? Distances et médiations des savoirs, Chasseneuil du Poitou, n. 11, 2015. Disponivel em: <journals.openedition.org/dms/1143>. Acesso em: 20 jan. 2020.

JOUET, J. Retour critique sur la sociologie des usages. Réseaux-Com. Tech. Sté. Paris, v. 18, n. 100, p. 487-521, 2000. Disponivel em: <https://doi.org/10.3406/reso.2000.2235>. Acesso em: 17 mai. 2020.

KNOERR, H. TIC et motivation en apprentissage/enseignement des langues. Une perspective canadienne, Cahiers de l'APLIUT, v. 24, n. 2, p.53-73, 2005. Interfaces da Educ., Paranaíba, v.11, n.32, p. 735 - 763, 2020 
Disponivel em: <http://journals.openedition.org/apliut/2889>. Acesso: 15 fev. 2020.

KUENZER, A. Z., MACHADO, L. R. de S. A pedagogia tecnicista. 1n: MELO, G. (org.). Escola Nova; tecnicismo na educação compensatória. São Paulo: Loyola, 1986.

LOPES, W. E. Soares . Andrew Feenberg e a bidimensionalidade da tecnologia. Rev. Filos. Aurora, Curitiba, v. 27, n. 40, p. 111-142, jan./abr. $2015 . \quad$ Disponivel em: $<$ https://periodicos.pucpr.br/index.php/aurora/article/view/550>. Acesso em: 28 nov. 2018.

MARCELO, C.; RIJO, D. Aprendizaje autorregulado de estudiantes universitarios: Los usos de las tecnologias digitales. RECIE, v. 3, n. 1, p. 6281, dec. 2019. Disponivel em: <https://revistas.isfodosu.edu.do/index.php/recie/article/view/141/143>. Acesso em: 19 dez. 2019.

MILHANO, Â. S. N.. A emergência da teoria crítica da tecnologia de Andrew Feenberg - por uma concepção democrática da Tecnologia. 2010. 78 f. Dissertação (Mestrado em Filosofia Moderna e Contemporânea) - Faculdade de Letras da Universidade do Porto, Portugal. Disponível em: $<$ https:// repositorio-125

aberto.up.pt/bitstream/10216/55873/2/tesemesangelomilhano000127203. pdf>. Acesso em: 06 out. 2019.

MANSOURI, M. Le jeu vidéo didactique ou serious game : processus de conception, ingénierie didactique et game design. 2019. 314 f. Tese (Sciences de l'éducation) - École doctorale "sociétés, humanités, arts et lettres" Université Côte d'Azur, France. Disponivel em: <https://tel.archivesouvertes.fr/tel-02498565/document>. Acesso em: 16 abr. 2020.

MOROZOV, E. To Save Everything, Click Here: The Folly of Technological Solutionism. New York: PublicAffairs, 2013.

PELGRUM, W. J.; LAW, N. ICT in education around the world: trends, problems and prospects. Fundamentals of educational planning, n. 77, Paris: UNESCO, 2003.

POUTS-LAJUS, S. Une question impossible, à propos de l'efficacité des TIC. Revue interacadémique Ac-TICE, Nancy, v. 17, n. 1, 2001.

ROSADO, L. A. da S.; FERREIRA, G. M. S.; CARVALHO, J. de S. Educação e tecnologia na literatura acadêmica on-line em português. In: FERREIRA, G. M. S.; ROSADO, L. A. S.; CARVALHO, J. S. (Org.) Educação e tecnologia: Interfaces da Educ., Paranaíba, v.11, n.32, p. 735 - 763, 2020 
abordagens críticas. Rio de Janeiro: Editora UNESA, 2017, p. 208-254. Disponível em: <https://ticpe.files.wordpress.com/2017/04/ebook-ticpe2017.pdf>. Acesso em: 10 jan. 2020.

RUSSEL, T. L. The no significant difference phenomenon as reported in 355 research reports, summaries and papers. Raleigh: North Carolina State University, 1999.

SALATINO, A. T.; BUENO, B. O. Entre mundos juvenis: o papel das tecnologias na escolarização de alunos das classes populares. ETD - Educ. Tem. Dig., Campinas, v. 17, n. 3, p. 576-595, set./dez. 2015. Disponivel em: <http://periodicos.sbu.unicamp.br/ojs/index.php/etd/article/view/863751 1>. Acesso em: 14 fev. 2020.

SANTOS, S.R.M.; FERREIRA, D. As tecnologias digitais de informação e comunicação e a didática multidimensional: por uma ressignificação necessária. Educ. Cult. Contemp., Rio de Janeiro, v. 17, n. 47, p. 12-31, jan./mar. 2020. Disponivel em: <http://periodicos.estacio.br/index.php/reeduc/article/view/7286/479665 $\underline{41}$ >. Acesso em: 22 fev. 2020.

SAVIANI, D. Escola e democracia: teorias da educação, curvatura da vara, onze teses sobre educação e politica. Campinas, SP: Autores Associados, 1999.

SELWYN, N. O uso das TIC na educação e a promoção de inclusão social: uma perspectiva crítica do Reino Unido. Educ. Soc., Campinas , v. 29, n. 104, p. 815-850, out. 2008. Disponivel em: <http://dx.doi.org/10.1590/S0101-73302008000300009 >. Acesso em: 20 dec. 2020

. Dez sugestões para melhorar a investigação académica em educação e tecnologia. Educ. Form. \& Tec., v. 9, n. 2, p. 3-9, dez. 2016. Disponivel em: <https://eft.educom.pt/index.php/eft/article/view/581>. Acesso em: 28 nov. 2019.

Educação e tecnologia: questões críticas. FERREIRA, Giselle. M. S. (trad.). In: FERREIRA, G. M. S.; ROSADO, L. A. S.; CARVALHO, J. S. (Orgs.) Educação e tecnologia: abordagens críticas. Rio de Janeiro: Editora UNESA, 2017, p. 85-103. Disponivel em: <https:/ / ticpe.files.wordpress.com/2017/04/ebook-ticpe-2017.pdf>. Acesso em: 22 set. 2019. 
SHULMAN, L. S. Those Who Understand: Knowledge Growth. Educ. res., Washington, vol. 15, n. 2 , p. 4-14, feb. 1986. Disponivel em: $<$ https://www.jstor.org/stable/i250140>. Acesso em: 11 jan. 2020.

SCHUHMACHER, V. R. N.; ALVES FILHO, J. de P.; SCHUHMACHER, E. As barreiras da prática docente no uso das tecnologias de informação e comunicação. Cienc. Educ., Bauru, v. 23, n. 3, p. 563-576, jul. 2017. Disponivel em: <https://doi.org/10.1590/1516-731320170030002>. Acesso em: 22 jun. 2020.

SOARES-LEITE, W. S.; NASCIMENTO-RIBEIRO, C. A. A inclusão das TICs na educação brasileira: problemas e desafios. Magis, Rev. Intern. Investig. Educ., v. 5, n. 10, p. 173-187, jul./dec. 2012. Disponivel em: $<$ https://www.redalyc.org/pdf/2810/281024896010.pdf $>$. Acesso em: 15 fev. 2020.

UNIVERSITÉ DE MONTPELIER. Approches pour créer des Serious games MOOC. Disponivel em: <https://www.youtube.com/watch?v=q1X0Br6Bm-g> Acesso em 16 jun. 2020.

VILLEMONTEIX, F. BÉZIAT, J. Le TNI à l'école primaire : entre contraintes et engagement, Revue Sticef, v. 20, p. 327-360, 2013. Disponível em: $<$ https://doi.org/10.3406/stice.2013.1071>. Acesso em 20 fev. 2020.

VILLEMONTEIX, F.; KHANEBOUBI, M. Étude exploratoire sur l'utilisation d'iPads en milieu scolaire : entre séduction ergonomique et nécessités pédagogiques. Revue Sticef, v. 20, p. 445-464, 2013. Disponivel em: $<$ https://doi.org/10.3406/stice.2013.1078>. Acesso em 20 fev. 2020.

ZASLAVSKY, A. Ação pedagógica, ação comunicativa e didática. Conjectura: Filos. Educ., Caxias do Sul, v. 22, n. 1, p. 69-81, jan.abr. 2017.2 Disponível em: <https://doi.org/10.18226/21784612.v22.n1.05>. Acesso em: 12 ago. 2019. 